DOI: http://doi.org/10.52716/jprs.v11i3.534

\title{
The Use of Nuclear Magnetic Resonance (NMR) Measurements and Conventional Logs to Predict Permeability for a Complex
}

\section{Carbonate Formation}

\author{
Raniah S. Alkhayyat ${ }^{* 1}$, Fadhil S. Kadhim ${ }^{2}$, Yousif AL-Dunainawi ${ }^{3}$ \\ ${ }^{1,2}$ Petroleum Technology Department / University of Technology-Iraq \\ ${ }^{3}$ Electronic and Computer Engineering Department Ministry of Higher Education and Scientific \\ Research- Iraq \\ ${ }^{*}, 1$ Corresponding Author E-mail: rania_shukri@yahoo.com, \\ ²fadhilkadhim47@yahoo.com, ${ }^{3}$ yousifky@gmail.com
}

Received 4/6/2020, Accepted 9/6/2021, Published 19/9/2021

This work is licensed under a Creative Commons Attribution 4.0 International License.

\begin{abstract}
$\underline{\text { Abstract }}$
Permeability is one of the most important property for reservoir characterization, and its prediction has been one of the fundamental challenges specially for a complex formation such as carbonate, due to this complexity, log analysis cannot be accurate enough if it's not supported by core data, which is critically important for formation evaluation. In this paper, permeability is estimated by making both core and $\log$ analysis for five exploration wells of Yammama formation, Nasiriyah oil field. The available well logging recorders were interpreted using Interactive Petrophysics software (IP) which used to determine lithology, and the petrophysical properties. Nuclear Magnetic Resonance (NMR) Measurements is used for laboratory tests, which provide an accurate, porosity and permeability measurements. The results show that the main lithology in the reservoir is limestone, in which average permeability of the potential reservoir units' values tend to range from 0.064275 in zone YA to 20.74 in zone YB3, and averaged porosity values tend to range from 0.059 in zone YA to 0.155 in zoneYB3. Zone YB3 is found to be the best zone in the Yammama formation according to its good petrophysical properties. The correlation of core-log for permeability and porosity produce an acceptable $\mathrm{R}^{\wedge} 2$ equal to $0.618,0.585$ respectively.
\end{abstract}

Keywords: Formation evaluation, well logs, carbonate formation, NMR, Core Analysis, Petrophysics, Porosity, Permeability. 


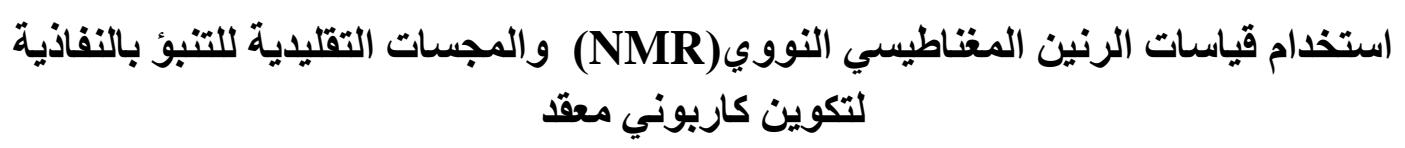

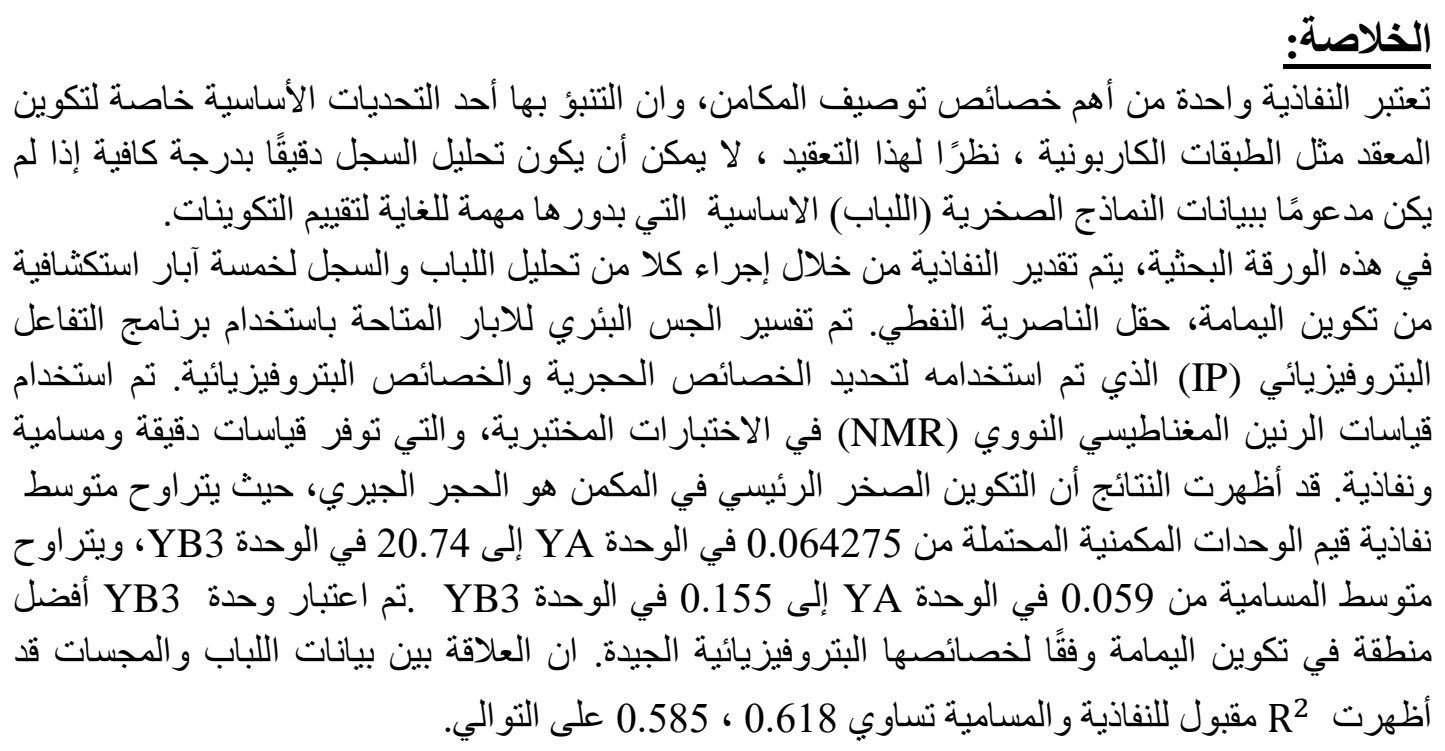

\section{Introduction}

Permeability is a porous medium property that tests the formation's capacity and ability to transmit fluids. The rock permeability, $\mathrm{k}$, is a very essential rock property as it influences the directional movement and flow rate of reservoir fluids in the formation [1].

Permeability determination in Carbonate reservoirs is a very complicated matter, since they are characterized by the extreme heterogeneity of permeability and porosity, often, multiple challenges present in the representation of these properties due to the heterogeneity attributed of texture, vugs, diagenesis, and multiple types of fractures. This complexity was the key driver for selecting the required measurements to make an appropriate characterization of the reservoirs. Log analysis with the combination of routine core data and well test data, have made some significant advancements in characterization the study formation [2].

LithoMetrixTM and GIT systems software were used to run rock core analysis on standard NMR equipment, it performs routine measurements such as T1 and T2based pore size distributions, porosity, permeability and fluid mobility calculations such as Free Fluid Index (FFI), Bound Volume Irreducible (BVI) and Clay Bound Water (CBW) [3]. 
On the other hand, the data collected from geological and geophysical surveys are used to formulate probable definitions and realizations of geological structure that may contain hydrocarbons, starting with digitizing logs and environmental corrections, determining lithology, and petrophysical properties estimation.

The aim of this study is to determine the permeability Yammama formation in Nasiriyah oil field, for a better evaluation and reservoir characteristics.

\section{Area of case study}

Nasiriyah oil field has been discovered in 1978 by The Iraq National Oil Company (INOC), It is located on the Arabian Platform, in a gently folded region, west of Zagros fold belt. This zone is characterized by NNW-SSE trending folds, with large anticlines with flanks that dip gently at around $2-3^{\circ} \mathrm{C}$. The field grouped within the Gharraf axis, which includes the undeveloped Gharraf and Rafidain fields. The field is operated by south oil through its Dhi Qar subsidiary and is located southern Iraq in Dhi Qar province. The field lies east of the River Euphrates, about 38 kilometers northwest of the city of Nasiriyah [4].

Yammama formation was discovered as a result of the seismic surveys attained by INOC, which demonstrate the structure of Nasiriyah field as a folded anticline trending NW-SE with a single dome. The first exploration well, Nasiriyah-1, was drilled in 1978, and the studied wells are NS-1, NS-2, NS-3, NS-4, and NS-5, NS oil field which is considered as a giant oil field in the south of Iraq as it is characterized by carbonate reservoirs [5].

Yammama consists mainly of limestone textures from mud-supported to grainsupported., which in most parts are clean, but there may be some dolomitic limestone and shale, Yammama was mainly divided into three main YA, YB and YC reservoir units and is separated by variable thickness impermeable layers, The reservoir unit YB is divided into three units YB-1, YB-2 and YB-3, and the largest reservoir is YB-3 [4]. 


\section{Open Access}

No. 32, September 2021, pp.82-98

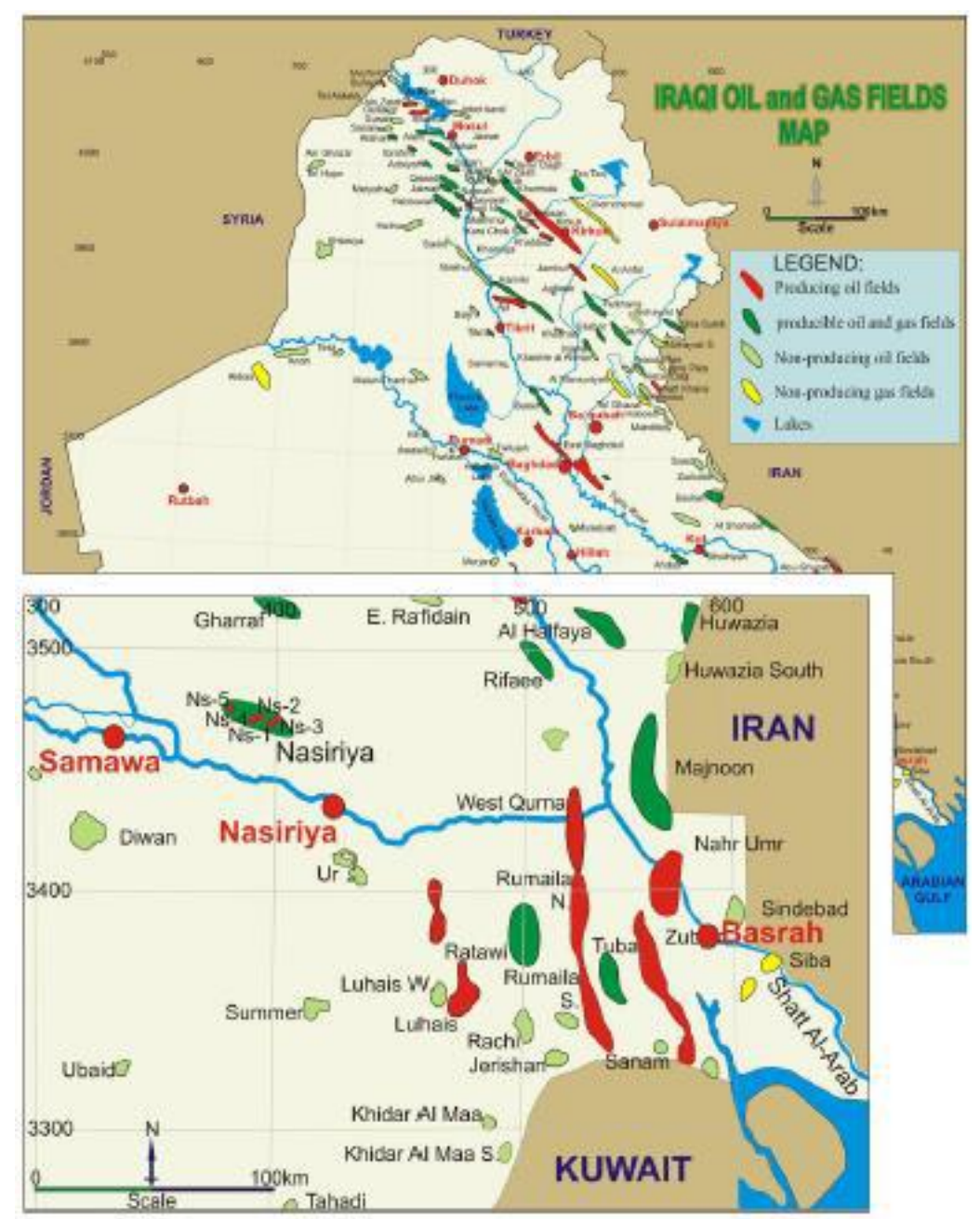

Fig. (1) Nasiriyah oil field location [6]

\section{Methodology}

Well log analysis has been made for the five wells, formation evaluation needed a lot of tests, laboratory experiments, and correlations, combined with log interpretation, Petrophysical properties were calculated to make a clearer picture of the two methods of calculation and the difference between them, and also to evaluate the reservoir zones, the work flow diagram is shown in Figure (6).

\section{Core analysis:}

\section{a. Core Sample preparation}

The purpose of the coring and core analysis is to minimize uncertainty in the assessment of the reservoir by providing in situ conditions representative 
information of the reservoir. Coring and core analysis are an integral part of the evaluation of formation and provide vital information that cannot be extracted from either log or productivity measurements. The laboratory tests started with:

1. cleaning samples, organic contaminants in solid environmental samples from natural and man-made sources are most of the time effectively extracted with organic solvents in a Soxhlet system and used as a separation technique from the solid matrix [7].

2. Drying is commonly performed in a regular oven or a vacuum oven at temperatures between $500 \mathrm{C}$ to $1050 \mathrm{C}$ [8], after cleaning sample, this was the second step in preparing the samples for the first NMR measurements. The dried sample should be stored in a desiccator, as the purpose of the desiccator is to or keep a core sample from becoming "wet" from atmospheric humidity. So after it heated with oven, must be cooled to room temperature in a desiccator [9].

\section{b. The T2 NMR Scan}

The T2 NMR Scan then started, right after completing system calibration, setting the temperature of NMR device to $35^{\circ} \mathrm{C}$, and entering the calculated core samples dimensions and weights. First test run is made by subjecting the dry core samples to short intense pulses of radio frequency electromagnetic radiation, the T2 NMR acquisition scan is used to measure the $\mathrm{T} 2$ pore size distribution.

\section{c. Core Sample Saturation}

In order to make the T2 NMR Analysis, core samples must be saturated with water first. The core samples are placed inside a vacuum container as shown in Fig.5, running vacuum pump, cores were saturated with fresh water, left for 15 days and then were weighted.

\section{d. The T2 NMR Analysis}

After making the first T2 NMR Scan, the saturated core is subjected again to a magnetic and activated by a quick radio frequency pulse (RF), NMR signals are produced from water. The NMR signal is constructed instantly after the pulse, which then falls away at the characteristic rate of decay or relaxation known as T2. The signal amplitude right away after the pulse presents the total quantity of existed fluid 
Open Access

No. 32, September 2021, pp.82-98

[10]. T2 NMR Analysis then has been made and permeability was estimated from the relaxation data using the Coates model and with the default model parameter, using carbonate T2 Scan card which designed for carbonate samples [11]. All of these calculations are carried out and reported automatically by the LithoMetrix software incorporated in GeoSpec instrument. As shown in Figure (2).

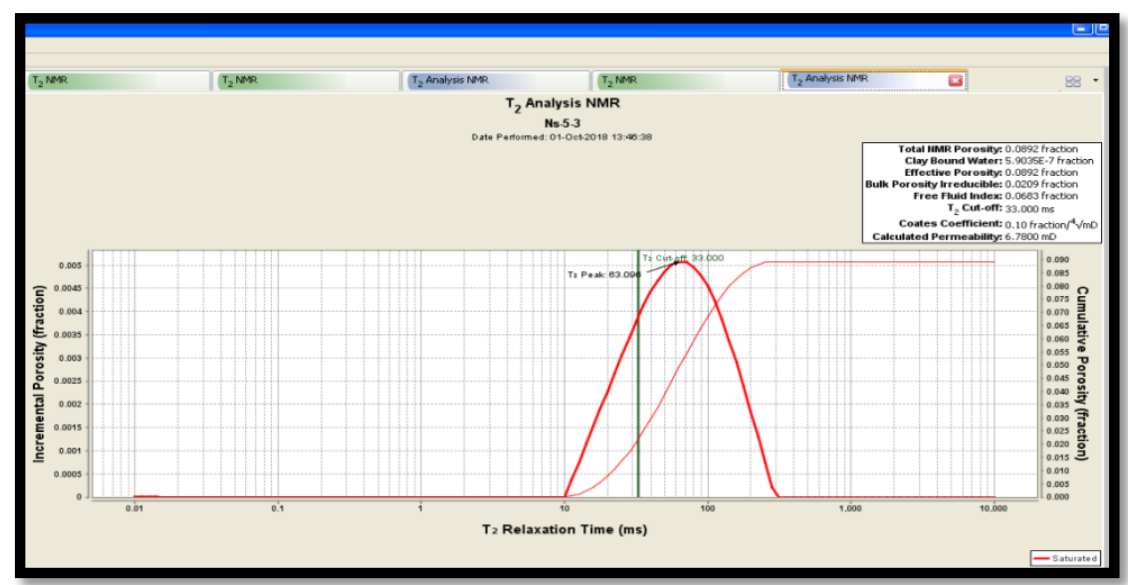

Fig. (2) T2 NMR Analysis result for core sample from NS-5 well
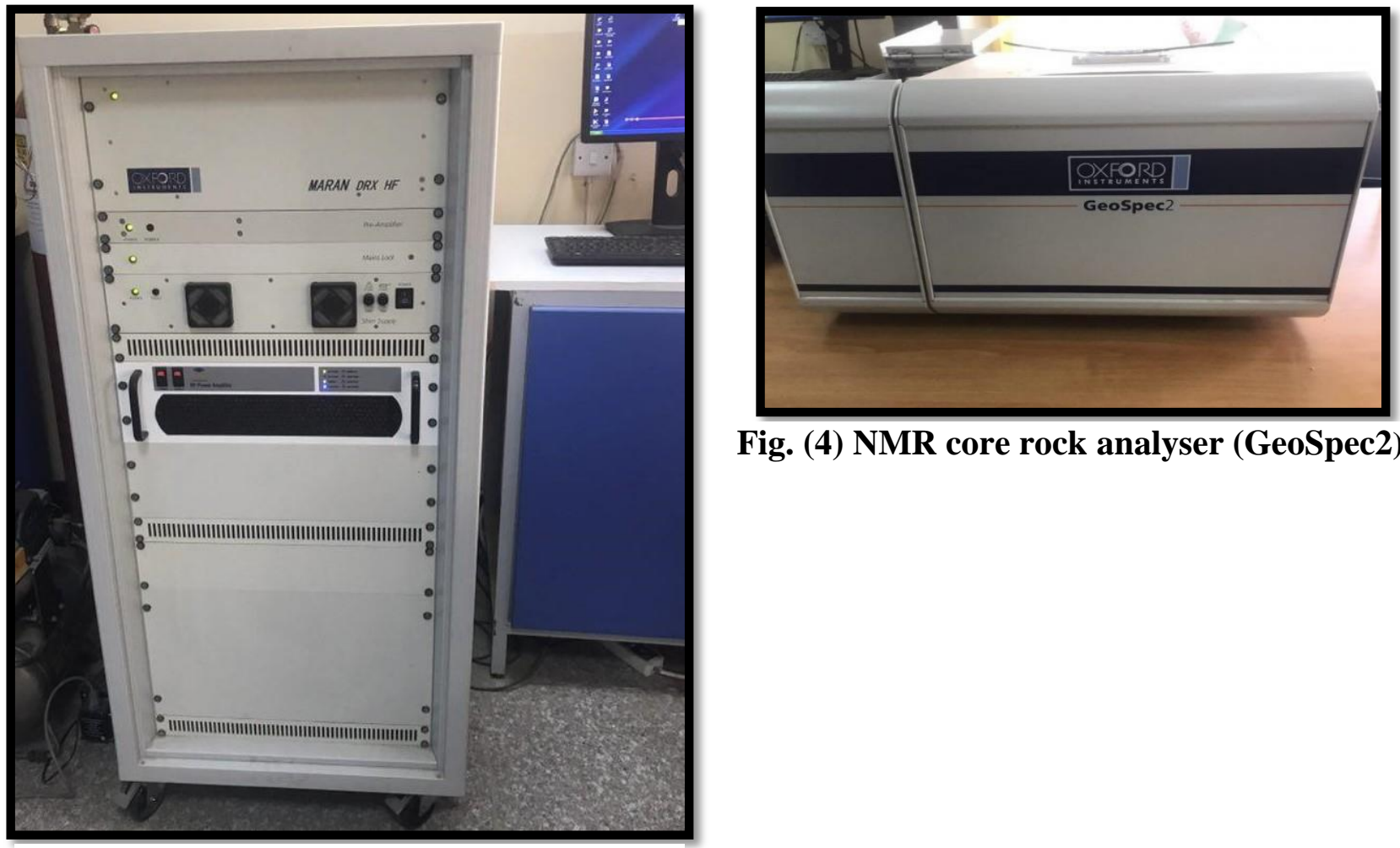

Fig. (4) NMR core rock analyser (GeoSpec2)

Fig. (3) NMR Oxford Instrument 
Open Access

No. 32, September 2021, pp.82-98

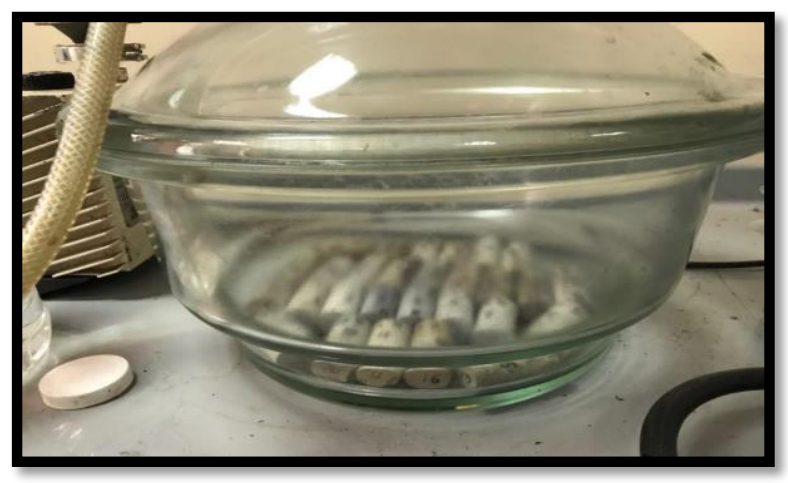

Fig. (5) Core saturation process using vacuum pump

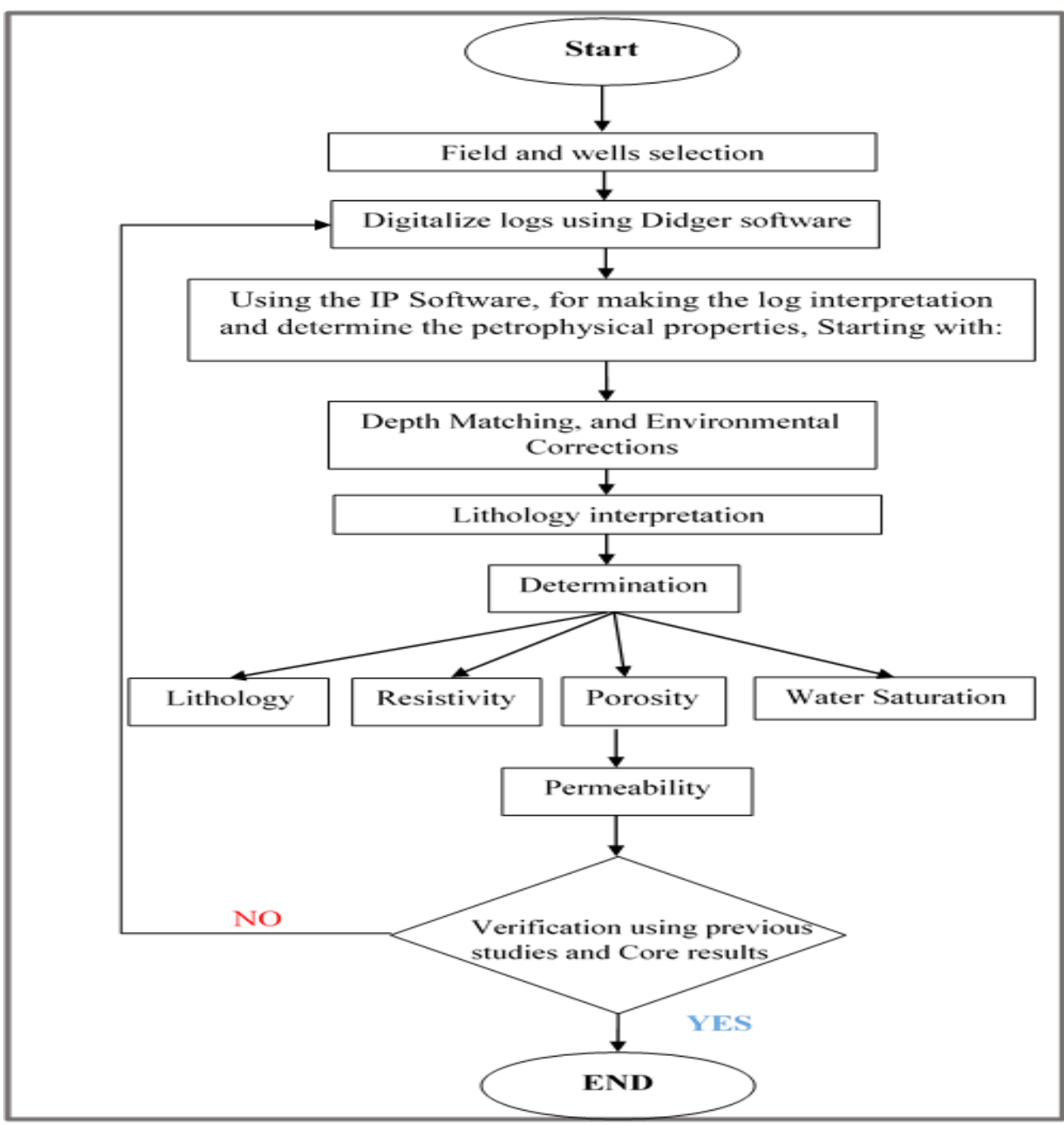

Fig. (6) Formation evaluation and permeability estimation methodology flow diagram 


\section{Results and Discussion:}

\subsection{Environmental Correction}

Environmental corrections have been made for available logs of the five wells using Schlumberger environmental correction charts 2005, which are provided with IP software, corrections have been produced per $0.25 \mathrm{~m}$ of depth in order to avoid inaccurate $\log$ interpretation performance. Actual properties of mud caliper log hydrostatic pressure and temperature gradient used to determine the accurate corrections.

The correction results are shown for the NS-1 well in Figure (7), from this figure, the red solid lines refer to the reading of the log tools, while the blue solid lines refer to the reading of the corrected log tools.

Gamma ray is corrected to mud properties and borehole condition, Induction, Shallow spherical resistivity, and Bulk density show no change between readings which indicate that the raw logs readings were not affected by drilling mud in the invention zone. Micro resistivity log and Neutron density log show a minor change in their readings due to drilling mud type, weight and resistivity, and the logging used tools or tool position.

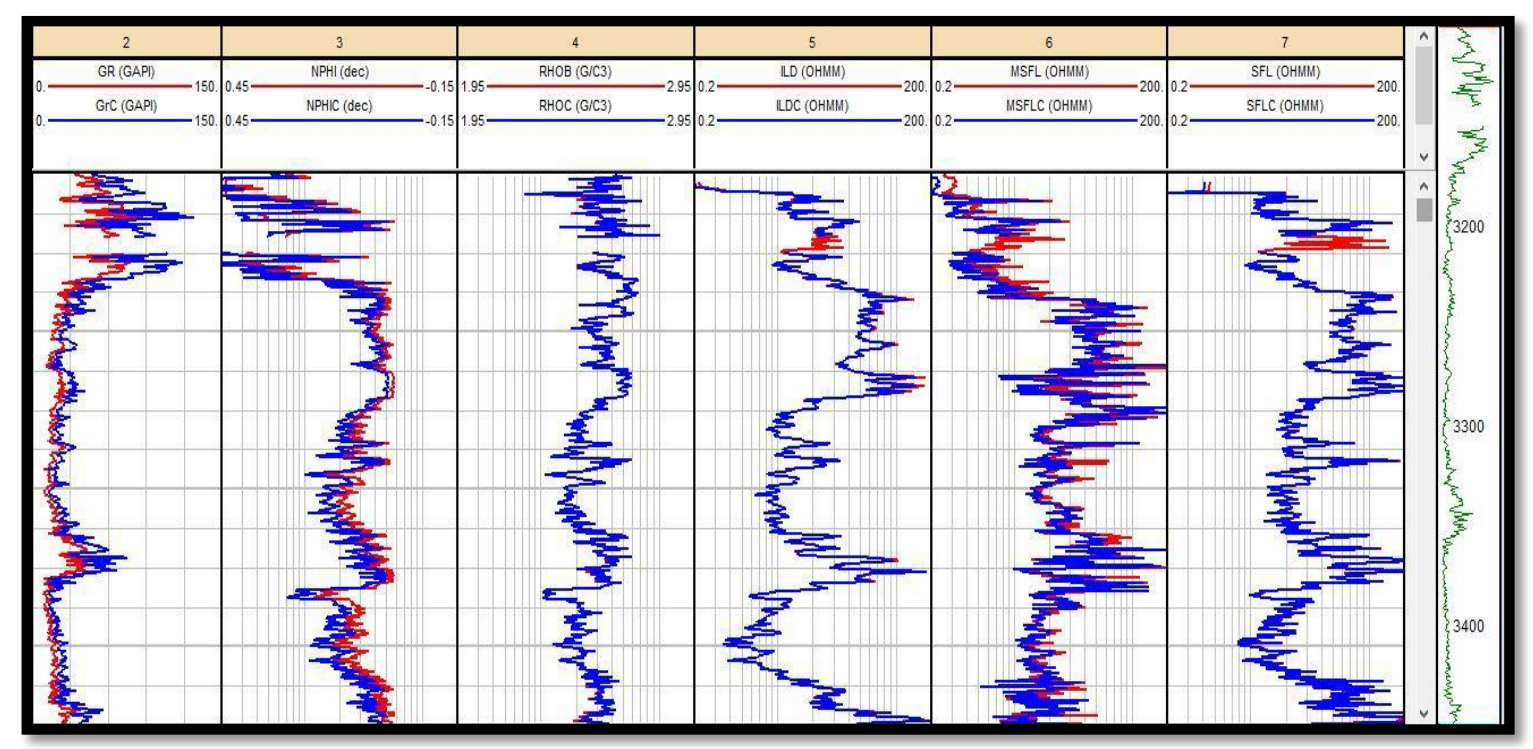

Fig. (7) Environmental correction log plot of NS-1. 


\subsection{Lithology Interpretation}

Lithology interpretation would be done using various logs, gamma rays, spontaneous potential, resistivity, and density logs. Mainly, the high reading of gamma rays indicates for shaly or shale formation, while the low reading of gamma rays indicates a clean formation such as sand, carbonate, etc. Interpretation of lithology is so essential in characterizing the reservoir, because if the interpretation of lithology is already incorrect, the next measurements such as porosity and water saturation will be a total mess.

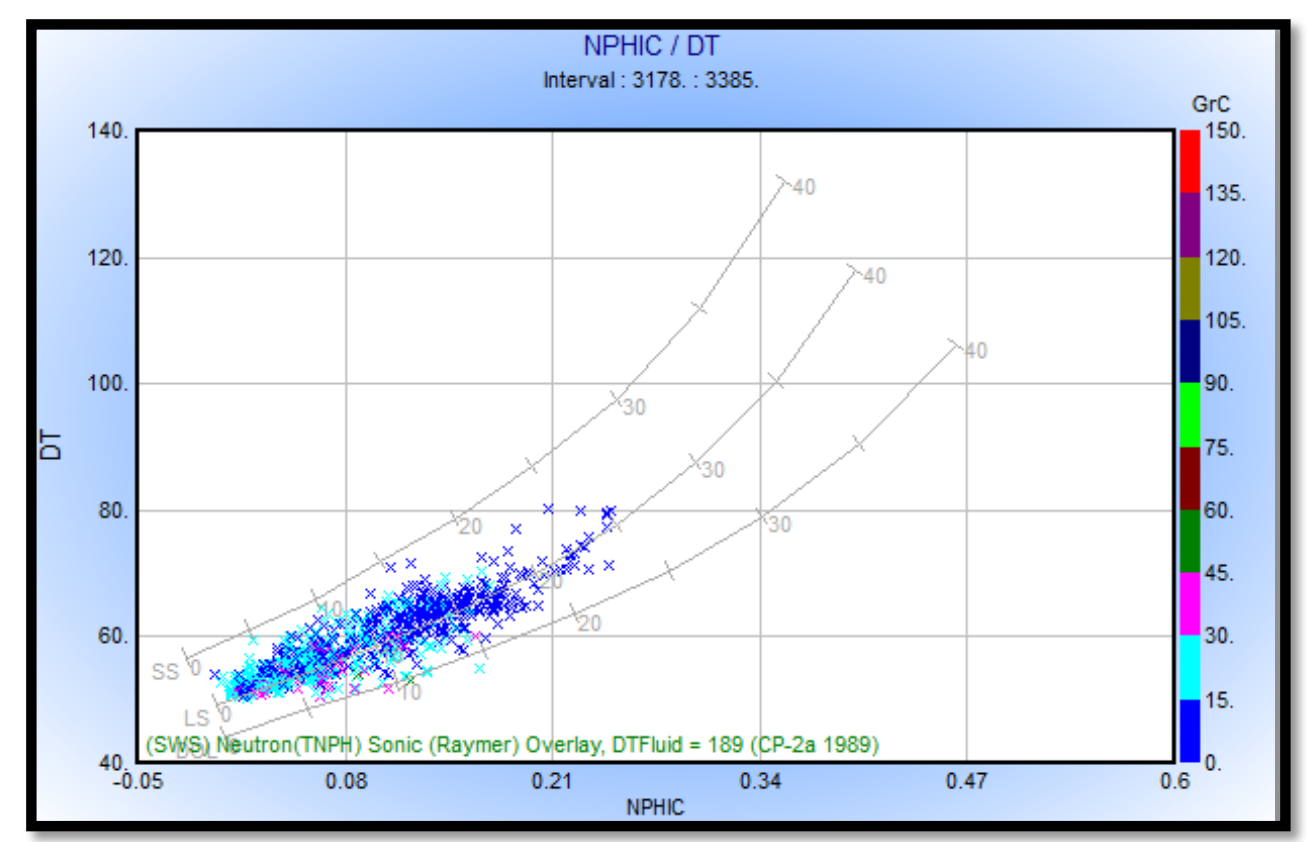

Fig. (8) Sonic - neutron lithology cross plot (NS-1)

The IP software is used to draw the sonic-neutron cross-plot for Yammama formation which is useful for displaying information for both porosity and lithology. Figure (8) demonstrates the cross-section of sonic neutrons for the Yammama formation. This figure shows the distinction between sandstone, limestone and dolomite lines which indicates good lithological resolution. In the right side, the gamma ray scale indicates the scale reading and colour of each rock type in the formation. For example, the white blue colour refers to dolomite and the blue sky colour refers to limestone. The results show that the main lithology is limestone and some points of sandstone as well as some dolomite spots. 


\subsection{Petrophysical Properties Estimation}

The volume of clay is estimated after the determination of lithology. Gamma ray $\log$ (VCLGR), SP log (VCLSP), neutron log (VCLN), resistivity log (VCLR), and other logs is used to calculate the volume of clay in the porous medium. After each indicator a result clay volume was obtained, Minimum shale volume (VCL) is calculated.

True Resistivity is also determined, one, two or more resistivity logs with different investigation depths were available, Rt determined from deep induction log (ILD), Resistivity measurements have been corrected previously as necessary for borehole effect, Rt is very important in detecting hydrocarbon zones and determining water saturation in the next stages.

Porosity is then estimated: only if the first step (lithology interpretation) is accurately estimated, porosity can be determined correctly. There are several methods to calculate porosity, such as using density log, neutron log, sonic log, but the most common method is the combination of neutron-density logs. The density and sonic porosities are calculated with the IP software, and then the total and effective porosity is estimated by the following equations:

$$
\text { Phi: } \begin{aligned}
\phi \mathrm{t} & =\sqrt{\frac{\varphi \mathrm{N}^{2}+\varphi \mathrm{D}^{2}}{2}} \\
\varphi \mathrm{e} & =\phi \mathrm{t}^{*}\left(1-V_{c l}\right)
\end{aligned}
$$

Where: $\varphi t$ : total porosity, $\varphi$ e: effective porosity, $\Phi \mathrm{N}$ : neutron porosity, $\varphi D$ : density porosity, andb $V_{c l}$ : clay volume.

After porosity is determined, it is important to calibrate it with core porosity, for a complex formation such as carbonate, the results and the core-log correlation is acceptable. The relationships between average Phicore and average Phicpi for Yammama formations are shown in Figure (9), from this relationships, the correlation coefficient $(\mathrm{R} 2=0.618)$ and the eq. is as follows:

$\mathrm{Phi}_{\text {cpi }}=0.3526 \mathrm{Phi}_{\text {core }}+0.044$ 
For the potential reservoir units of Yamama formation, Table (1) shows the average values of porosity of each zone, these zones have average porosity tend to range from 0.059 in YA to 0.155 in YB3, and Figures (11) to (15) shows the log view of the 5 wells. The variations between the core porosity value and the log can be the variation between the properties of mud filtrate and formation water [10], also the presence of vugs, fractures and the heterogeneity of the formation.

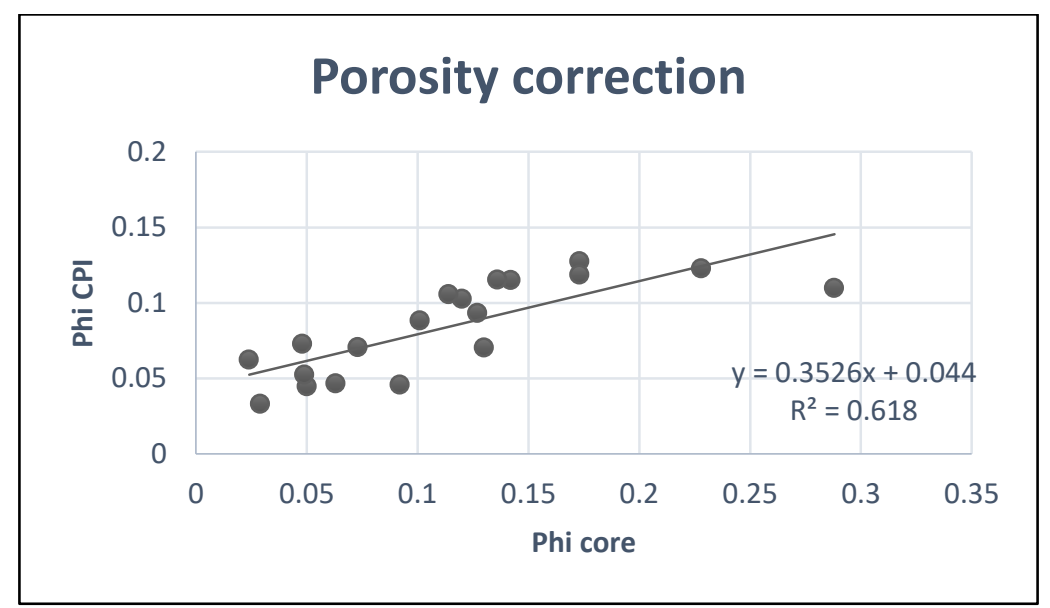

Fig. (9) Correlation between Ava. Phi core data and ava. Phi CPI data

Table (1) Average Porosity values of the potential reservoir zones

\begin{tabular}{|c|r|r|r|r|r|r|}
\hline & \multicolumn{1}{|c|}{ NS1 } & \multicolumn{1}{c|}{ NS2 } & \multicolumn{1}{c|}{ NS3 } & \multicolumn{1}{c|}{ NS4 } & \multicolumn{1}{c|}{ NS5 } & \multicolumn{1}{c|}{ Ava. } \\
\hline YA & 0.07102 & 0.081 & 0.059529 & 0.0632 & 0.076417 & 0.0702332 \\
\hline YB1 & 0.101 & 0.1121 & 0.0928 & 0.09608 & 0.091101 & 0.0986162 \\
\hline YB2 & 0.14109 & 0.1184 & 0.10019 & 0.109718 & 0.135 & 0.1208796 \\
\hline YB3 & 0.15383 & 0.1532 & 0.1492 & 0.1204 & 0.155 & 0.146326 \\
\hline YC & 0.15493 & 0.154 & 0.11949 & 0.1223 & 0.11145 & 0.132434 \\
\hline
\end{tabular}

Water saturation has been estimated using Indonesian model in IP software. This model had been derived originally to study water saturation in carbonate reservoir, as it used for calculating effective water saturation in shaly formations that are independent of the shale distribution in the reservoir, so, the overestimation by Archie equation due to the presence of shale is avoided [12].

Finally, permeability is estimated using Schlumberger model by IP software as well, the determined lithology is limestone, and from the log view of the 5 wells; Figures (9) to (13), and the potential reservoir units of Yamamah formation; Table 
(2), which show the average values of permeability of each zone , these zones has a permeability values tend to range from 0.064275 in YA to 20.74 in YB3, YB3 can be considered as the main zone due to it's petrophysical prtoperties.

After core data has been estimated, and averaged, a correlation has been set to correct the data with log results, as Figure (8). with the equation below:

Kcpi $=1.3048$ Kcore+ 0.57

Table (2) Average Permeability values of the potential reservoir zones

\begin{tabular}{|c|c|c|c|c|c|c|}
\hline & NS1 & NS2 & NS3 & NS4 & NS5 & ava \\
\hline YA & 0.601 & 7.54 & 1.42 & 0.064275 & 1.7252 & 2.270095 \\
\hline YB1 & 1.5 & 1.22 & 1.323 & 0.231 & 2.465 & 1.3478 \\
\hline YB2 & 5.5 & 9.5 & 2.5012 & 5.52 & 14.87 & 7.57824 \\
\hline YB3 & 12.7573 & 14.575 & 2.9075 & 7.9851 & 20.74 & 11.79298 \\
\hline YC & 15.925 & 9.1117 & 7.4104 & 6.1 & 5.6896 & 8.84734 \\
\hline
\end{tabular}

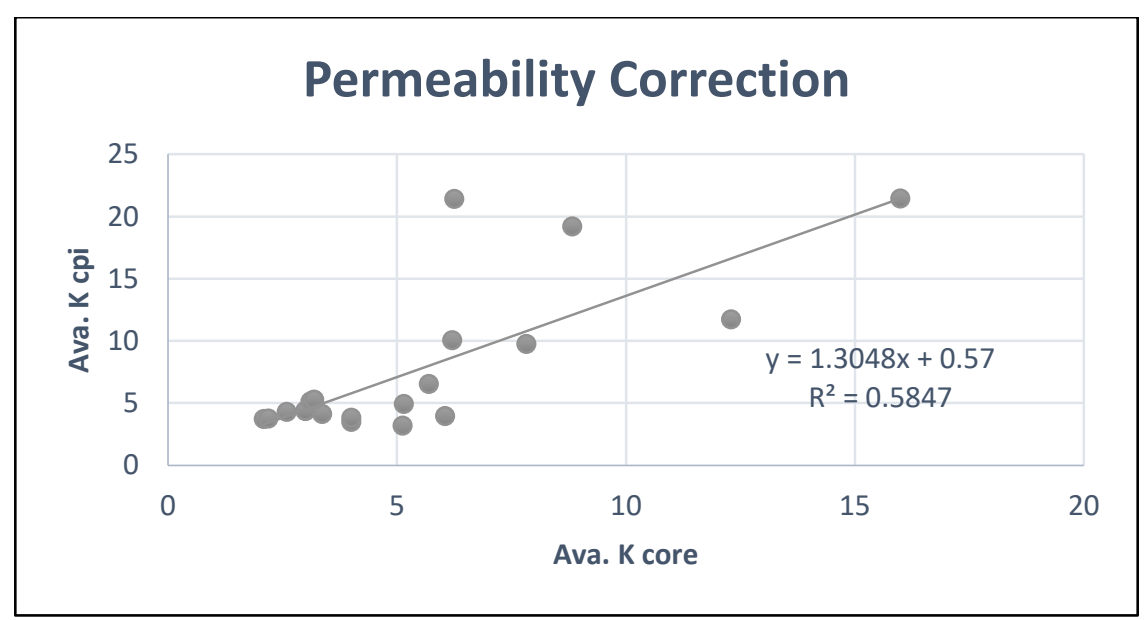

Fig. (10) The correlation between Ava. permeability core data and CPI data 
Journal of Petroleum Research and Studies

Open Access

No. 32, September 2021, pp.82-98

jepse

P- ISSN: 2220-5381

E- ISSN: 2710-1096

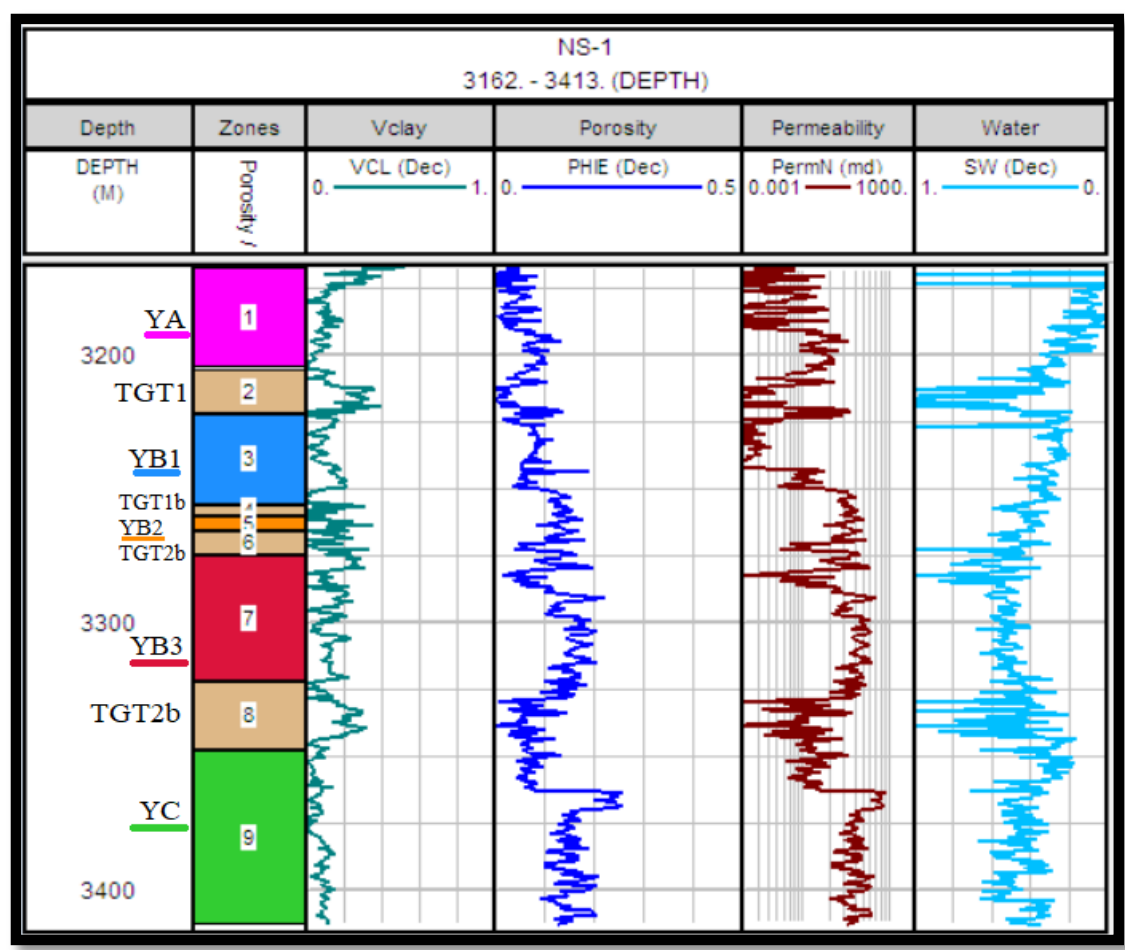

Fig. (11) CPI for NS1

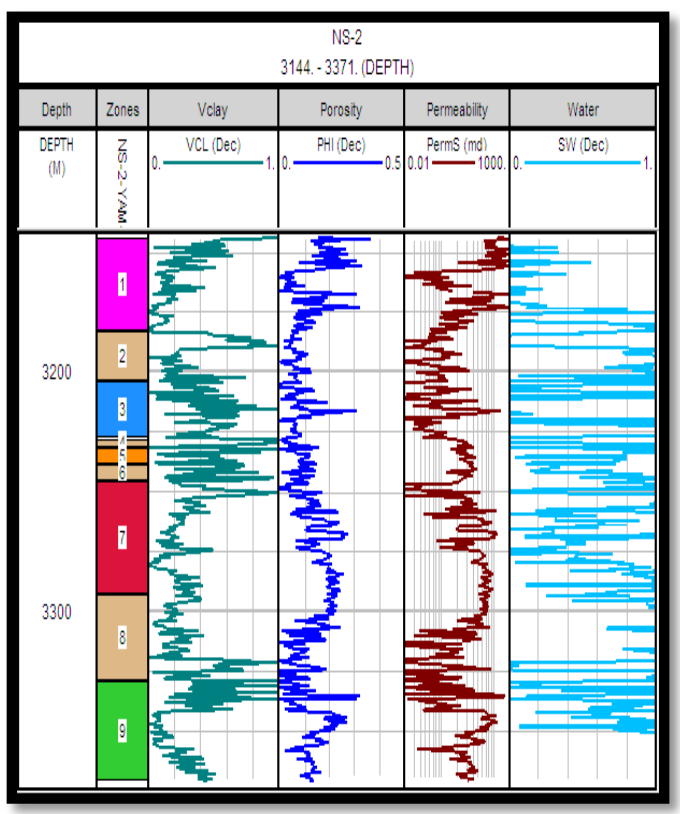

Fig. (12) CPI for NS2

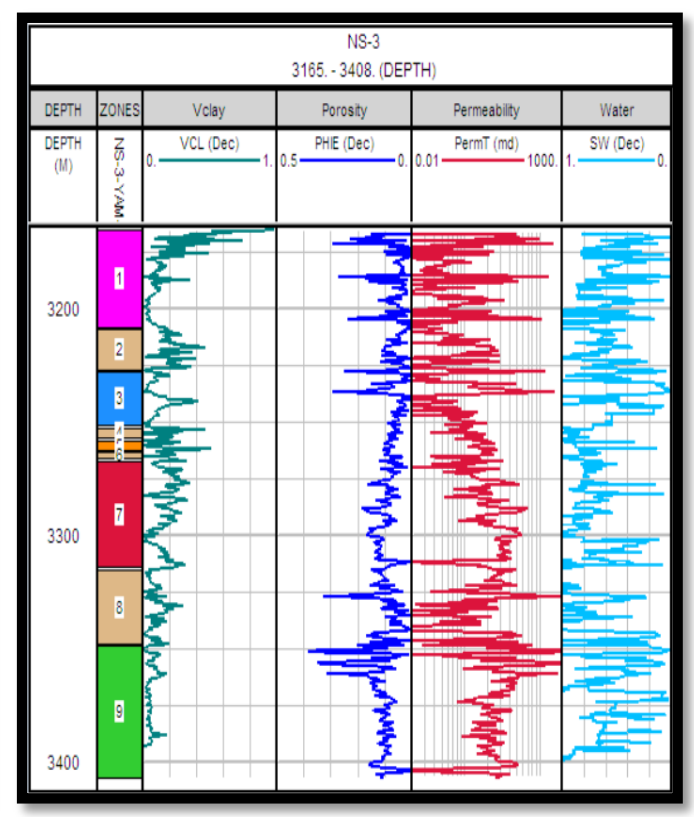

Fig. (13) CPI for NS3 


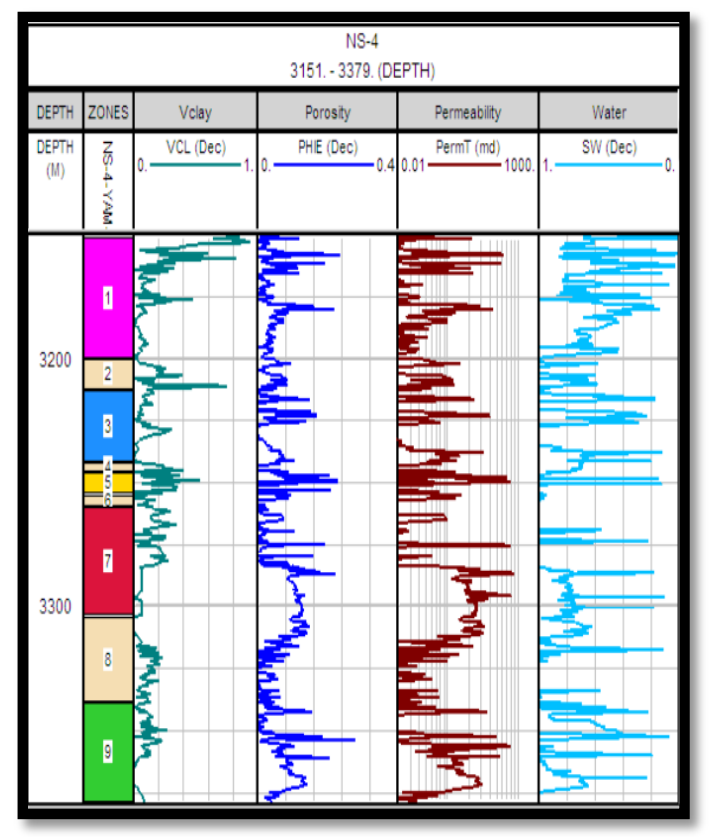

Fig. (14) CPI for NS4

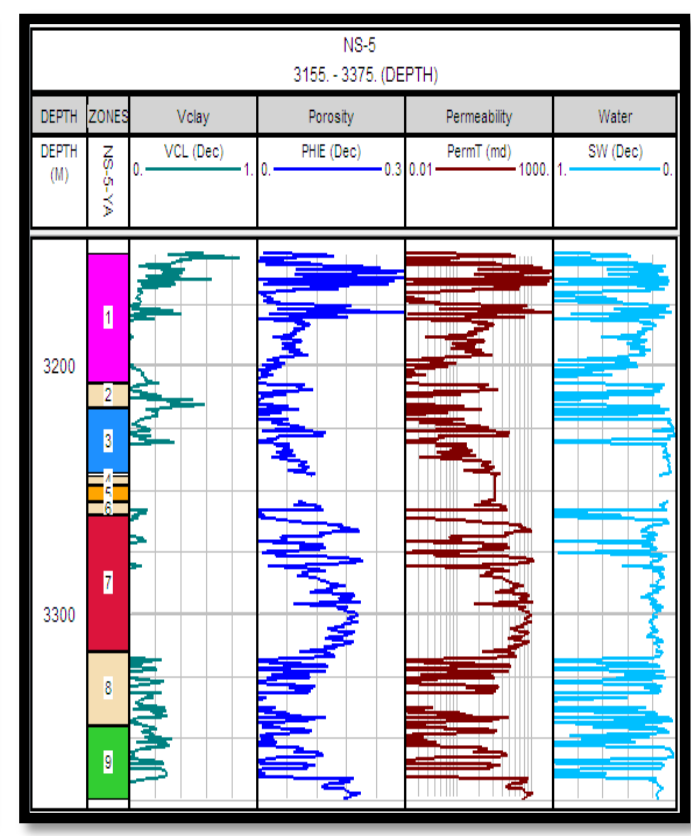

Fig. (15) CPI for NS5

\section{Conclusions}

In this study, Interactive Petrophysics (IP) software is used to determine the petrophysical properties of Yammama formation in Nasiriyah oil field, the log analysis results show that the main lithology in the reservoir is limestone, in which permeability averaged values tend to range from 0.064275 in YA to 20.74 in YB3, and porosity averaged values tend to range from 0.059 in YA to 0.155 in YB3, YB3 is considered the best zone in the Yammama formation according to its good petrophysical properties, while YA unit is found to be poor, and for YB1 and YB2 are fair.

Permeability are measured by using Nuclear Magnetic Resonance (NMR), and it estimate the porosity as well, then by which the log data has been corrected, relationships is produced with $\mathrm{R}^{2}$ equal $0.618,0.585$ for porosity and permeability respectively, it's considered to be acceptable for a complex formation such as carbonate. 
Open Access

\section{Nomenclature}

APE: Absolute percentage error

CPI Computer processed interpretation

GR: Gamma ray

IP Interactive Petrophysics

NMR Nuclear Magnetic Resonance

PHI: Porosity

SP: $\quad$ Spontaneous potential

RT True Resistivity

SW: Water saturation 


\section{$\underline{\text { References }}$}

[1] F. M. Mania, "Estimation Of Permeability In Siliciclastic Reservoirs From Well Log Analysis And Core Plug Data; Based On The Data From An Exploration Well Offshore Norway",NTNU University, MSc. report, NTNU Trondheim, 2017.

[2] A. Mohebbi, R. Kamalpour, K. Keyvanloo, and A. Sarrafi, "The Prediction of Permeability From Well Logging Data Based on Reservoir Zoning, Using Artificial Neural Networks in One of an Iranian Heterogeneous Oil Reservoir,” Pet. Sci. Technol., vol. 30, no. 19, pp. 1998-2007, 2012.

[3] O. I. Plc, GeoSpec core analysis GeoSpec A Design Evolution Complete Cutting Edge Solutions from the Industry Leaders. 2015.

[4] Anfal Kareem, "Reservoir study of Yammama formation in Nasiriya Field by using modern software", thesis, Petroleum Engineering, Baghdad University, 2013..

[5] F. S. Kadhim, "Cementation Factor And Carbonate Formation Properties Correlation From Well Logs Data For Nasiriya Field," Thesis, Universiti Teknologi Malaysia, 2016.

[6] Amer Jassim Al-Khafaji, "The Mishrif, Yamama, and Nahr Umr reservoirs petroleum system analysis, Nasiriya oilfield, Southern Iraq,” Arab. J. Geosci., vol. ISSN 1866-, no. DOI 10.1007/s12517-014-1277-2, 1866.

[7] The Origin of the Soxhlet Extractor William B. Jensen Vol. 84 No. 12 December 2007 • Journal of Chemical Education 1913.

[8] O. Torsæter, M. Abtahi, " Experimental Reservoir Engineering Laboratory Work Book " Norwegian University of Science and Technology, 2000.

[9] R. E. Sturgeon et al., "Determination of moisture content of single-wall carbon nanotubes," no. May 2014.

[10] Oxford Instruments Magnetic Resonance. "NMR - Nuclear Magnetic Resonance in Core Analysis". $\quad$ AZoM. 
https://www.azom.com/article.aspx?ArticleID=5721.

[11] G. I. T. Systemslithometrix and U. Manual, "GIT Systems and LithoMetrix User Manual," 2013.

[12] K. H. Jassim and J. A. Al-sudani, "Re-evaluation of Petro physical Properties in Yammama Formation at Nasiriya Field”, Iraqi Journal of Chemical and Petroleum Engineering, Vol.20 No.3 (September 2019) 59 - 66, EISSN: 2618-0707, PISSN: $1997-4884$ 